\title{
CD45(-) Acute Lymphoblastic Leukemia Characterized by Migratory Arthritis, Thrombocytosis, Thrombosis and Early Relapse: Case Report and Literature Review
}

Michelle Gurnari Tawa, Patty Ku and Theodore Zwerdling*

Department of Pediatrics, Section Hematology/Oncology, University of California, Davis Medical Center 2516 Stockton Blvd, Sacramento CA, 95817

\begin{abstract}
We describe an unusual case of pre-B cell Acute Lymphoblastic Leukemia (ALL) presenting with recurrent migratory arthritis, thrombocytosis without peripheral blasts, who developed a saphenous vein thrombosis prior to starting chemotherapy. Immunophenotyping, some molecular analysis and early bone marrow response (day 15 of induction) were consistent with good prognosis. However, the patient developed very early Central Nervous System (CNS) relapse two months after induction chemotherapy. The constellation of clinical presentation, laboratory evaluations and response to treatment may allow identification of new prognostic features designed to stratify treatment and predict outcome.
\end{abstract}

\section{Introduction}

Musculoskeletal pain and bone radiographic abnormalities can be clinical manifestations of leukemia. Children may undergo multiple studies to establish primary orthopedic or infectious pathologies before malignancy is considered, particularly if the overall clinical picture of the patient does not coincide with common signs and symptoms of malignant disease [1]. Diagnostic delays also occur when hematologic indexes are normal in the context of unexplained orthopedic complaints.

We report a pediatric patient presenting with recurrent migrating arthritis, bone pain, radiographic abnormalities, and thrombocytosis found to have CD45- pre-B cell ALL. This patient developed an early CNS relapse.

\section{Case Presentation}

A 3-year-old male presented with intermittent tactile fevers, right elbow and forearm pain and joint effusion, 3 weeks post-accidental trauma. Physical exam was remarkable only for inflammation surrounding the right elbow with guarding. Osteomyelitis had been diagnosed based on Magnetic Resonance Imaging (MRI) findings and pus aspirated from the joint. A culture and gram stain from incision and drainage (I\&D) site were negative for organisms; however, cell count was not performed. Clindamycin intravenous therapy was implemented. At this time, laboratories were: White Blood Count (WBC) $3.8 \mathrm{~K} /$ $\mathrm{mm}^{3}$, hemoglobin $10.3 \mathrm{~g} / \mathrm{dL}$, platelets $959 \mathrm{~K} / \mathrm{mm}^{3}$, Absolute Neutrophil Count (ANC) $1.33 \mathrm{~K} / \mathrm{mm}^{3}$. No blast forms were reported and several inflammatory markers were elevated. Symptoms appeared to partially improve on antibiotic treatment, however, 2 weeks later the patient returned with similar symptoms affecting the left elbow. Revaluation with MRI and bone scan suggested multifocal osteomyelitis and a left elbow I\&D yielded no organisms; cell count from the joint fluid was not evaluated. Complete Blood Count (CBC) was unchanged and several antibiotic therapies considered. After some apparent clinical improvement the patient was discharged with a diagnosis of recurrent multifocal osteomyelitis on oral amoxicillin to empirically treat Kingella spp.

Four days later he again presented, with unresolved left elbow inflammation, bilateral knee pain with right unilateral swelling, and reported tactile fever. No testicular masses were found. Initial labs with this admission were unchanged. Due to the recurrent and migratory joint effusions progressing on antibiotics without known implicated organism, investigation into malignancy ensued. Urine catecholamines, lactic acid dehydrogenase and uric acid were normal. A bone marrow examination was hypercellular with approximately $80 \%$ blast forms, morphologically identified as lymphoblasts. Immunophenotypic analysis by flow cytometry identified cells TDT+, CD19+, CD10+, CD22+, CD38+, intracellular CD79a+, and interestingly, CD45-. All myeloid markers were non-reactive. Lumbar puncture demonstrated no blast forms. Fluorescent In Situ Hybridization (FISH) analysis found $60 \%$ of nuclei with trisomy 4 and 10, one signal for TEL gene region, and four signals for AML1 gene region. A subclone was observed with $10 \%$ of nuclei demonstrating trisomy 9 and 17, tetrasomy 10 and three signals each for BCR, PBX1 and MLL. A FISH panel for myelodysplasia was negative and bone marrow karyotype normal. Repeat $\mathrm{CBC}$, now 2 months after the initial presenting complaint, was notable for newly apparent $6 \%$ peripheral blasts with persistent thrombocytosis. During the evaluation, the patient developed a right superficial saphenous vein thrombosis and was briefly anticoagulated.

The results were consistent with precursor B-cell ALL and induction treatment initiated with vincristine, dexamethasone, and intrathecal methotrexate. L-asparaginase was replaced with a single dose of adriamycin because of the known thrombus. A day 15 bone marrow examination found less than $5 \%$ blasts and the patient achieved morphologic remission on day 29. Minimum Residual Disease (MRD) by flow analysis was $0.15 \%$. Throughout induction therapy, all signs and symptoms resolved but platelets remained elevated, ranging 548-723K/ $\mathrm{mm}^{3}$. Two months later, the patient developed an isolated CNS relapse and underwent reinduction chemotherapy.

*Corresponding author: Ted Zwerdling, Department of Pediatrics, Section Hematology/Oncology University of California, Davis Medical Center, 2516 Stockton Blvd, Sacramento CA, 95817, Tel: 916-734-2781; Fax: 916-451-3014; E-mail: Theodore.zwerdling@ucdmc.ucdavis.edu

Received December 06, 2011; Accepted January 08, 2011; Published January 13, 2011

Citation: Tawa MG, Ku P, Zwerdling T (2012) ACD45(-) Acute Lymphoblastic Leukemia Characterized by Migratory Arthritis, Thrombocytosis, Thrombosis and Early Relapse: Case Report and Literature Review. J Blood Disord Transfus 3:114. doi:10.4172/2155-9864.1000114

Copyright: ( 2012 Tawa MG, et al. This is an open-access article distributed under the terms of the Creative Commons Attribution License, which permits unrestricted use, distribution, and reproduction in any medium, provided the original author and source are credited. 
Citation: Tawa MG, Ku P, Zwerdling T (2012) ACD45(-) Acute Lymphoblastic Leukemia Characterized by Migratory Arthritis, Thrombocytosis, Thrombosis and Early Relapse: Case Report and Literature Review. J Blood Disord Transfus 3:114. doi:10.4172/2155-9864.1000114

Page 2 of 3

\section{Discussion}

Several facets of this case are notable. Diagnosing ALL required the pursuit of malignancy despite uncommon presenting features including primary orthopedic complaints of ambiguous etiology and laboratory values atypical for leukemia. Later, peculiar characteristics of the tumor cell immunophenotype and cytogenetics were observed, which conferred a mixed prognosis. However, the patient developed a very early CNS relapse.

Bone or joint pain can be one of the presenting symptoms in leukemic children. Patients may be incorrectly diagnosed and treated for osteomyelitis or juvenile inflammatory arthritis several months prior to ALL diagnosis [2]. Additionally, osteomyelitis itself is a known presenting symptom and complication of ALL [3]. The patient described here had symptoms consisting of migrating joint effusions and inflammation; preliminarily receiving a nominal diagnosis of osteomyelitis based on clinical and radiographic findings. However, bacterial organisms must be implicated for this diagnosis and response to antimicrobial therapy expected. Here, an organism was not definitively implicated and symptoms progressed despite multiple trials of antibiotics.

Both nonbacterial osteomyelitis and its subtype of Chronic Recurrent Multifocal Osteomyelitis (CRMO) are distinguished from osteomyelitis in that sterile bone lesions are characteristic. CRMO is rare among children with osteomyelitis. Multifocal lesions occur in $6-8 \%$ of cases [4], and it has very rarely been reported in ALL [5,6]. About 6\% of patients with acute leukemia and musculoskeletal complaints present with joint effusions [1].

Initial $\mathrm{CBC}$ in this patient was not suspicious for leukemia, demonstrating only mild anemia and leukopenia. Peripheral blasts did not appear until months later. Thrombocytosis was remarkable, found persistently throughout both workup and treatment. It has been reported that nearly normal hematologic values are associated with certain cases of ALL involving bone pain $[2,7,8]$. One retrospective review of 296 patients [8] found that those presenting with the primary complaint of bone pain, compared with those with predominant symptoms of another type, tended towards nearly normal hemoglobin concentration, leukocyte, absolute neutrophil, and platelet counts. A lower percentage of peripheral blasts were also noted, delaying diagnosis. Forty-six percent of the patients with significant musculoskeletal pain had platelet count greater than $150 \times 10^{9} / \mathrm{L}$, while only $12 \%$ without such pain had similar platelet counts.

Platelets may respond to inflammation as other acute phase reactants but few studies have commented on thrombocytosis at presentation of leukemia. Blatt et al. [9] reported a prevalence of $3.7 \%$ of children with ALL presenting with platelet counts greater than $400 \mathrm{~K} / \mathrm{mm}^{3}$ (7 of 217). All patients were Caucasian males and maintained platelet counts of greater than $20 \mathrm{~K} / \mathrm{mm}^{3}$ throughout induction therapy. Two experienced complications during induction (cavernous sinus thrombosis; gastrointestinal perforation) and high-risk features were identified in 3 patients (1 Philadelphia chromosome, 2 T-cell disease). Three patients did not have peripheral blasts and reported normal karyotype. The patient reported here initially did not have peripheral blasts and did have platelet counts higher than those in the study. See Table 1.

Superficial thrombosis occurred in this patient with no known prothrombotic history other than thrombocytosis prior to induction therapy. We interpret his thrombosis as a manifestation of thrombocytosis and a potential hypercoagulable state attributable to malignancy [10] The majority of data surrounding thrombosis in ALL relays the risk incurred during therapy, especially after exposure to L'Asparaginase. A meta-analysis of 17 studies found a $5.2 \%$ risk of thrombosis in pediatric

\begin{tabular}{|c|c|c|c|c|c|c|c|c|c|}
\hline & atient & $\begin{array}{l}\text { Age (months) } \\
\text { sex } \\
\text { race }\end{array}$ & Plts $^{*}$ & $\begin{array}{c}\text { Absolute periph- } \\
\text { eral } \\
\text { blasts }\end{array}$ & $\begin{array}{l}\text { \%Blasts in } \\
\text { BMA }^{\star \star *}\end{array}$ & $\mathrm{Hb}$ ** & $\begin{array}{l}\text { Immunologic } \\
\text { markers }\end{array}$ & Chromosomes & Outcome (months) \\
\hline & 1 & $\begin{array}{c}5 \\
\text { male } \\
\text { Caucasian }\end{array}$ & 643 & 0 & 85 & 10.8 & Non-T, J5- & Normal & $\begin{array}{c}\text { Testicular Relapse } \\
(54)\end{array}$ \\
\hline & 2 & $\begin{array}{c}46 \\
\text { male } \\
\text { Caucasian }\end{array}$ & 520 & 78 & 46 & 9.8 & Non-T, J5+ & Unknown & $\mathrm{NED}^{+}(2)$ \\
\hline & 3 & $\begin{array}{c}84 \\
\text { male } \\
\text { Caucasian }\end{array}$ & 509 & 16424 & 86 & 8.7 & Non-T, J5+ & $\begin{array}{l}\text { Hypodiploid } \\
\text { t21 (one meta- } \\
\text { phase) }\end{array}$ & NED (2) \\
\hline & 4 & $\begin{array}{c}53 \\
\text { male } \\
\text { Caucasian }\end{array}$ & 508 & 4564 & 87 & 12.7 & $\mathrm{~T}$ & 46XY, 1q- & BM relapse(19) \\
\hline & 5 & $\begin{array}{c}72 \\
\text { male } \\
\text { Caucasian }\end{array}$ & 498 & 0 & 34 & 12.6 & $\mathrm{~T}$ & Normal & NED (29) \\
\hline & 6 & $\begin{array}{c}70 \\
\text { male } \\
\text { Caucasian }\end{array}$ & 464 & 4284 & 98 & 13 & Non-T, J5+ & $\mathrm{Ph}+$ & NED (42) \\
\hline & 7 & $\begin{array}{c}25 \\
\text { male } \\
\text { Caucasian }\end{array}$ & 408 & 0 & 81 & 12.3 & Unknown & Normal & NED (36) \\
\hline This $\mathrm{F}$ & Report & $\begin{array}{c}36 \\
\text { male } \\
\text { Native American }\end{array}$ & 959 & 0 & 80 & 10.3 & CD45(-) & $\begin{array}{l}\text { Trisomies } \\
\text { MLL } \\
\text { TEL-AML }\end{array}$ & CNS Relapse (2) \\
\hline $\begin{array}{l}{ }^{*} \mathrm{Plts} \\
{ }^{* *} \mathrm{Hb} \\
{ }^{* * *} \mathrm{BMA} \\
{ }^{+} \mathrm{NED}\end{array}$ & $\begin{array}{l}=\text { Plat } \\
=\text { Hem } \\
=\text { Bon } \\
=\text { no e }\end{array}$ & $\begin{array}{l}\left(10^{3} / \mathrm{mm}^{3}\right) \\
\text { obin }(\mathrm{g} / \mathrm{dL}) \\
\text { arrow Aspiration } \\
\text { nce of diseases }\end{array}$ & & & & & & & \\
\hline
\end{tabular}

Table 1: Reported cases of Thrombocytosis in Pediatric ALL [9]. 
Citation: Tawa MG, Ku P, Zwerdling T (2012) ACD45(-) Acute Lymphoblastic Leukemia Characterized by Migratory Arthritis, Thrombocytosis, Thrombosis and Early Relapse: Case Report and Literature Review. J Blood Disord Transfus 3:114. doi:10.4172/2155-9864.1000114

Page 3 of 3

patients [11]. Presumably due to the rarity of thrombocytosis in ALL, there are no studies which specifically comment on the relationship between increased platelets and pre-treatment thrombotic risk. Some studies suggest a hypercoagulable state in childhood ALL, both from increased procoagulant activity and decreased anticoagulant factors [1215]. However, this remains controversial [14].

Immunophenotyping of the leukemic cells was unusual by the absence of CD45 surface immunoreactivity. CD45, a surface tyrosine phosphate protein expressed on $\mathrm{T}$ - and B-cells, is undetectable in $12.9 \%$ to $14 \%$ of newly diagnosed B-cell precursor pediatric ALL, [16,17] and less so in T-Cell disease. Its absence has been associated with good prognosis $[5,6,16]$. CD45- is also associated with hyperdiploidy, independently known to suggest good prognosis [16-19]. Further studies are needed to determine a relationship between CD45 expression vis-à-vis the clinical presentation and response to treatment of this patient.

The patient here also demonstrated mixed cytogenetic analysis with trisomies 4 and 10, TEL-AML rearrangement (favorable) and MLL rearrangement found in $\sim 12 \%$ of blasts (unfavorable). Results of the Day 15 bone marrow were consistent with a rapid early response to treatment but with MRD detectable $(0.15 \%)$ on day 29 . The presence of these conflicting prognostic markers required treatment as higher risk classification, in accordance with the Children's Oncology Group risk stratification schema. The very early CNS relapse (week 8) which occurred is extremely unusual and suggests other unknown factors involved in the leukemogenic process. The $\mathrm{t}(1: 19) / \mathrm{TCF} 3 / \mathrm{PBX} 1$ translocation is associated with increased risk of CNS relapse, but more favorable event-free survival [20]. Although this patient did not have a TCF3/PBX1 fusion, he did have 3 copies of PBX1, suggesting an important role in leukemogenesis or response to therapy.

\section{Conclusion}

We introduce a case of a child found to have ALL with an unusual clinical presentation and laboratory findings who responded poorly to treatment. This case suggests additional, as of yet unidentified factors, contribute to the overall prognosis of leukemia. This report also highlights the continuing need for careful clinical observations and their correlation with laboratory findings. Stratification schema subsequently linked to treatment options are likely to benefit from this approach.

\section{References}

1. Sinigaglia R, Gigante C, Bisinella G, Varotto S, Zanesco L, et al. (2008) Musculoskeletal Manifestations in Pediatric Acute Leukemia. J Pediatr Orthop 28: $20-28$

2. Kai T, Ishii E, Matsuzaki A, Okamura J, Ikuno Y, et al. (1996) Clinical and prognostic implications of bone lesions in childhood leukemia at diagnosis. Leuk Lymphoma 23: 119-123.

3. Murphy RG, Greenberg ML (1988) Osteomyelitis in Pediatric Patients with Leukemia. Cancer 62: 2628-2630.

4. Nelson JD (1990) Acute osteomyelitis in children. Infect Dis Clin North Am 4: 513-522

5. Tavil B, Secmeer G, Balc YI, Tezer H, Aksoy C, et al. (2010) Chronic Recurrent Multifocal Osteomyelitis as the First Presentation of Acute Lymphoblastic Leukemia in a 2 year old Boy. J Pediatr Hematol Oncol 32: 151-152.

6. Bartakke S, Abdelhaleem M, Abla O (2007) Childhood acute Iymphoblastic leukaemia simulating multifocal osteomyelitis. $\mathrm{Br} \mathrm{J}$ Haematol 139: 2

7. Ma SK, Chan GC, Ha SY, Chiu DC, Lau YL, et al. (1997) Clincial Presentation, Hematologic Features and Treatment Outcome of Childhood Acute Lymphoblastic Leukemia: a Review of 73 cases in Hong Kong. Hematol Oncol 15: 141-191.

8. Jonsson OG, Sartain P, Ducore JM, Buchanan GR (1990) Bone pain as an initial symptom of childhood acute lymphoblastic leukemia: Association with nearly normal hematologic indexes. J Pediatr 117: 233-237.

9. Blatt J, Penchansky L, Horn M (1989) Thrombocytosis as a presenting feature of acute lymphoblastic leukemia in childhood. Am J Hematol 31: 46-49.

10. Bajzar L, Chan AK, Massicotte MP, Mitchell LG (2006) Thrombosis in children with malignancy. Curr Opin Pediatr 18: 1-9.

11. Caruso V, lacoviello L, Di Castelnuovo A, Storti S, Mariani G, et al. (2006) Thrombotic complications in childhood acute lymphoblastic leukemia: a metaanalysis of 17 prospective studies comprising 1752 pediatric patients. Blood 108: $2216-2222$

12. Giordano P, Molinari AC, Del Vecchio GC, Saracco P, Russo G, et al. (2010) Prospective study of hemostatic alterations in children with acute lymphoblastic leukemia. Am J Hematol 85: 325-330.

13. Dixit A, Kannan M, Mahapatra M, Choudhry VP, Saxena R (2006) Roles of protein $\mathrm{C}$, protein $\mathrm{S}$, and antithrombin III in acute leukemia. Am J Hematol 81: 171-174.

14. Troy K, Essex D, Rand J, Lema M, Cuttner J (1991) Protein C and S levels in acute leukemia. Am J Hematol 37: 159-162.

15. Ruud E, Holmstrøm H, Brosstad F, Wesenberg F (2006) Children with acute lymphoblastic leukaemia have high plasma levels of total homocysteine at time of diagnosis. Scand J Clin Lab Invest 66: 67-78.

16. Nakamura A, Tsurusawa M, Kato A, Taga T, Hatae Y, et al. (2001) Prognostic impact of CD45 antigen expression in high-risk, childhood B-cell precursor acute lymphoblastic leukemia. Leuk Lymphoma 42: 393-398.

17. Behm FG, Raimondi SC, Schell MJ, Look AT, Rivera GK, et al. (1992) Lack of CD45 antigen on blast cells in childhood acute lymphoblastic leukemia is associated with chromosomal hyperdiploidy and other favorable prognostic features Blood 79: 1011-1016.

18. Kaneko Y, Hayashi Y, Sakurai M (1981) Chromosomal findings and their correlation to prognosis in acute lymphocytic leukemia. Cancer Genet Cytogenet 4: 227-235.

19. Pui CH, Relling MV, Downing JR (2004) Acute lymphoblastic leukemia. N Eng J Med 350: 1535-1548.

20. Jeha S, Pei D, Raimondi SC, Onciu M, Campana D, et al. (2009) Increased risk for CNS relapse in pre-B cell leukemia with the t(1;19)/TCF3-PBX1. Leukemia 23: 1406-1409. 